\title{
Revisiting Connectivity in Copular Sentences
}

\author{
Yael Sharvit \\ University of Connecticut
}

\section{Introduction}

The received wisdom regarding Connectivity in copular sentences (e.g., Higgins 1973) is that specificational copular sentences exhibit Connectivity, but predicational copular sentences do not. This paper argues, contra the received wisdom, that some predicational copular sentences exhibit Connectivity as well, as illustrated by (1), where her is bound by no woman.

(1) A parody of her $r_{i}$ mother is the only thing no woman ${ }_{i}$ wants to be.

More accurately, this paper claims that (1) is ambiguous between a specificational and a predicational reading, and that the bound reading of her arises in both. The predicational reading is made available by the presence of only. When only is missing (as in (2)), only the specificational reading survives.

(2) A parody of her $\mathrm{i}_{\mathrm{i}}$ mother is the thing/what no woman $\mathrm{i}_{\mathrm{i}}$ wants to be.

The ambiguity of (1) has so far gone unnoticed because: (i) it is not easy to detect; and (ii) the received wisdom creates an expectation that what brings about a bound reading of sentences such as (1) is their specificational reading.

\section{Background and Main Claims}

The received wisdom is illustrated by (3). (3a), where the post-copular phrase contains no "bindable" expressions, is ambiguous. By contrast, (3b), whose post-copular phrase contains a bound pronoun is unambiguously specificational. (3c) is ambiguous just like (3a). This means that only on the specificational reading of The only thing no woman wants to be is a parody of her mother can her be interpreted as a variable bound by no woman, as if it were c-commanded by no woman. On the predicational of this sentence, her is interpreted referentially.

a. The only thing no woman wants to be is irritating.

$==>$ (that property $\mathrm{P}$ such that $\{\mathrm{P}\}=\{\mathrm{Q} \mid$ no woman $\mathrm{x}$ wants that $\mathrm{Q}(\mathrm{x})\})=($ that $\mathrm{P}$ such that for all $\mathrm{x}, \mathrm{P}(\mathrm{x})$ iff $\mathrm{x} \in\{\mathrm{y} \mid$ irritating $(\mathrm{y})\})$.

(Specificational)

For very helpful comments, I thank the participants of: SALT XIX, Yale Linguistics Colloquium (March 2009), The Linguistics Colloquium at the Hebrew University of Jerusalem (January 2009) and the General Exam Workshop at UConn (Spring 2009). 
$==>$ (that property $\mathrm{P}$ such that $\{\mathrm{P}\}=\{\mathrm{Q} \mid$ no woman $\mathrm{x}$ wants that $\mathrm{Q}(\mathrm{x})\}) \in\{\mathrm{y} \mid \operatorname{irritating}(\mathrm{y})\}$.

(Predicational)

b. The only thing no woman ${ }_{i}$ wants to be is a parody of her $r_{i}$ mother.

$==>$ (that property $\mathrm{P}$ such that $\{\mathrm{P}\}=\{\mathrm{Q} \mid$ no woman $\mathrm{x}$ wants that $\mathrm{Q}(\mathrm{x})\})=($ that property $\mathrm{P}$ such that for all $\mathrm{x}, \mathrm{P}(\mathrm{x})$ iff $\mathrm{x} \in\{\mathrm{y} \mid$ parody-of-y's-mother(y)\}).

(Specificational)

$=/=>$ (that property $\mathrm{P}$ such that $\{\mathrm{P}\}=\{\mathrm{Q} \mid$ no woman $\mathrm{x}$ wants that $\mathrm{Q}(\mathrm{x})\}) \in\{\mathrm{y} \mid$ parody-of-y's-mother(y) $\}$.

(Predicational)

c. The only thing no woman ${ }_{i}$ wants to be is a parody of her ${ }_{k}$ mother.

$=\Rightarrow$ There is some female $\mathrm{z}$ such that: (that property $\mathrm{P}$ such that $\{\mathrm{P}\}$ $=\{\mathrm{Q} \mid$ no woman $\mathrm{x}$ wants that $\mathrm{Q}(\mathrm{x})\})=$ (that $\mathrm{P}$ such that for all $\mathrm{x}$, $\mathrm{P}(\mathrm{x})$ iff $\mathrm{x} \in\{\mathrm{y} \mid$ parody-of-z's-mother $(\mathrm{y})\}) . \quad$ (Specificational)

$=\Rightarrow$ There is some female $\mathrm{z}$ such that: (that property $\mathrm{P}$ such that $\{\mathrm{P}\}=$ $\{\mathrm{Q} \mid$ no woman $\mathrm{x}$ wants that $\mathrm{Q}(\mathrm{x})\}) \in\{\mathrm{y} \mid$ parody-of-z's-mother(y)\}. (Predicational)

The absence of a predicational reading in (3b) may perhaps be blamed on the fact that properties don't have mothers. But this doesn't mean that a copular sentence with a pronoun that is bound by a quantifier that doesn't c-command it on the surface is never compatible with a predicational reading, because some copular sentences are precisely like that. ${ }^{1}$ For example, (1) - the "inverse" counterpart of (3b) - where her is interpreted as bound by no woman, is ambiguous (as we will see). Its specificational reading is the same as that of (3b), and its predicational reading is perfectly sensible, and roughly says the following: (that property $\mathrm{P}$ such that: for all $\mathrm{x}, \mathrm{P}(\mathrm{x})$ iff $\mathrm{x} \in\{\mathrm{y} \mid$ parody-of-y's-mother $(\mathrm{y})\}) \in\{\mathrm{Q} \mid$ no woman $\mathrm{x}$ wants that $\mathrm{Q}(\mathrm{x})$ and there is no $\mathrm{Q}^{\prime} \neq \mathrm{Q}$ such that no woman $\mathrm{x}$ wants that $\mathrm{Q}^{\prime}(\mathrm{x})$ \}.

Showing that (1) is intuitively ambiguous turns out to be a complicated task. To facilitate the process, let us introduce some assumptions and definitions. Consider the copular sentences in $(4 \mathrm{a}, \mathrm{b})$, where the pre-copular phrase is a definite superlative phrase. Their corresponding LF templates are $(5 \mathrm{a}, \mathrm{b})$. We assume that the semantic type of the pre-copular phrase is 'e'. (5a) is specificational (as is the corresponding (4a)): it has an expression of type ' $\mathrm{e}$ ' after the copula - a type that matches that of the pre-copular phrase. (5b) is predicational (as is the corresponding (4b)): it has a predicate (type $<\mathrm{e}, \mathrm{t}>$ ) after the copula - "predicated of" the denotation of the pre-copular phrase.

(4) a. The only/tallest/first woman John dated was Sally.

b. The only/tallest/first woman John dated was (an) American.

a. [[DP1 the [NP1 only/P-est/first [NP1 $\left.\ldots]]]\left[\mathrm{VP} b e_{\mathrm{SPEC}}[\mathrm{DP} 2 \ldots]\right]\right]$

b. [[DP1 the [NP1 only/P-est/first [NP1' ... ]]] [VP $\left.\left.b e_{\mathrm{PRED}}[\mathrm{DP} 2(a)[\mathrm{NP} 2 \ldots]]\right]\right]$

\footnotetext{
${ }^{1}$ Whether properties have mothers is probably irrelevant anyway, as The only thing no dog wants to be is a parody of itself is ambiguous: on the specificational reading, itself is bound by no dog (which doesn't c-command itself on the surface), whereas on the predicational reading, itself is bound by the only thing no dog wants to be (which does c-command itself on the surface).
} 


\begin{tabular}{|c|c|c|}
\hline \multirow{7}{*}{ In $(5 a, b)$} & Node & Type \\
\hline & the & $<<\mathrm{e}, \mathrm{t}>, \mathrm{e}>$ \\
\hline & only/P-est/first & $<<\mathrm{e}, \mathrm{t}>,<\mathrm{e}, \mathrm{t}>>$ \\
\hline & NP1' & $<\mathrm{e}, \mathrm{t}>$ \\
\hline & NP1 & $<\mathrm{e}, \mathrm{t}>$ \\
\hline & DP1 & e \\
\hline & VP & $<\mathrm{e}, \mathrm{t}>$ \\
\hline \multirow[t]{2}{*}{ In $(5 a)$} & $b e_{\mathrm{SPEC}}$ & $<\mathrm{e},<\mathrm{e}, \mathrm{t}>>$ \\
\hline & DP2 & $\mathrm{e}$ \\
\hline \multirow[t]{2}{*}{$\operatorname{In}(5 b)$} & $b e_{\text {PRED }}$ & $<<\mathrm{e}, \mathrm{t}>,<\mathrm{e}, \mathrm{t}>>$ \\
\hline & DP2 & $\langle\mathrm{e}, \mathrm{t}\rangle$ \\
\hline
\end{tabular}

Let us call those copular sentences that have the form [[DP1 the [NP1 only/P-est/first NP1']] [vp be [DP2 ...]]] (e.g., (4) and (5)), only-standards. We refer to the pre-copular phrase in an only-standard as DP1 and to the post-copular phrase as DP2. Following Partee $(1986,2000)$, we assume that the type of DP1 is not required to be ' $\mathrm{e}$ '; it can be any type (this is motivated by the intuition that the subject in (3), for example, denotes a property - the property no woman wants to have). For any type $\sigma$, if DP1 is of type $\sigma$, then a specificational reading arises when the copula is $b e_{\text {SPEC }}$ and DP2 is of type $\sigma$; and a predicational reading arises when the copula is $b e_{\text {PRED }}$ and DP2 is of type $<\sigma, t>.^{2}$

The sentence in (6) is the result of reversing the order between DP1 and DP2 in the specificational only-standard example in (4a).

Sally was the only/tallest/first woman John dated.

Let us call the inverse counterparts of only-standards (e.g., (6)), that have the form [[DP2 ... ] [ $\mathrm{VP}$ be [DP1 the [NP1 only/P-est/first [NP1'... ]]]]], only-inverses. We refer to the pre-copular phrase in an only-inverse as DP2 (to emphasize the correspondence between the pre-copular phrase in only-inverses and the post-copular phrase in their only-standard counterparts). We also refer to the post-copular phrase in an only-inverse as DP1 (to emphasize the correspondence between the post-copular phrase in only-inverses and the pre-copular phrase in their only-standard counterparts). Our claim about sentences such as (6) (which will be spelled out in detail in Section 3) is that it is ambiguous: it has a specificational LF (akin to (5a)) and a predicational LF (akin to (5b)).

a. $\left[[\mathrm{DP} 2\right.$ Sally $]\left[\mathrm{vP}\right.$ be $e_{\mathrm{SPEC}}[\mathrm{DP} 1$ the $[\mathrm{NP} 1$ only $\left.[\mathrm{NP} 1, \ldots]]]\right]$

b. [[DP2 Sally] [VP be $e_{\mathrm{PRED}}[\mathrm{DP} 1$ [NP1 only [NP1, ... ]]]]]

In (7a), DP2 and DP1 are both of type e, and a specificational reading arises. In (7b) the definite determiner in DP1 is invisible to semantic interpretation. This means that NP1 (whose type is $\langle\mathrm{e}, \mathrm{t}>$ ) serves as the predicate that applies to Sally (whose type is e), and a predicational reading arises. By contrast, since (5a) is the

\footnotetext{
2In Partee (1986) it is suggested that DP1 in an only-standard can be "predicated of" the post-copular expression (contra the view advocated here). Partee (2000) considers some arguments against that suggestion. We come back to this issue in Section 4.5.
} 
only available LF of (4a), we predict that the only-standard The only woman John dated was Sally is unambiguously specificational.

As we will see, an extension of the semantic approach to Connectivity (Jacobson 1994, Sharvit 1999, Heller 2002) correctly predicts that whenever a Connectivity effect arises in a specificational only-standard (e.g., The only thing no woman wants to be is a parody of her mother), the same effect shows up in its only-inverse counterpart (see (1)), in both its specificational reading (i.e., the reading obtained from the LF where the is visible to semantic interpretation; cf. (7a)) and its predicational reading (i.e., the reading obtained from the LF where the is invisible to semantic interpretation; $\mathrm{cf} .(7 \mathrm{~b})$ ).

Section 3 shows that only-inverses are ambiguous, and spells out a semantic theory of this ambiguity. Section 4 discusses the fact that the ambiguity persists, as predicted by our semantic theory, in only-inverses that exhibit Connectivity. Section 5 discusses the shortcomings of syntactic approaches to Connectivity.

\section{The Ambiguity of Only-inverses}

This section shows that some - but crucially not all - definite descriptions can easily function as predicates in post-copular position. This restricted class of definite descriptions includes the class of the only/P-est/first-descriptions. It follows that only-inverses have a predicational reading.

Some definite expressions may lose their existence presuppositions in post-copular position (see, among others, Fodor 1970 and Rothstein 2004).

a. We don't have a president, so I am certain John is not the president.

b. We definitely have a president; I don't know if our president is Bill or someone else, but I am certain John is not the president.

In (8a), the underlined expression cannot pick out someone who is a (unique) president, because the preceding text - We don't have a president - establishes that there is no such individual. In (8b), by contrast, the underlined expression can pick out someone who is a (unique) president (because the preceding text - We definitely have a president - establishes that there is such an individual). Therefore, the underlined expression in (8a) is a predicative expression, and the underlined expression in ( $8 b)$ is, or at least can be, a non-predicative expression.

Importantly, the president cannot function as a predicate when it appears in a pre-copular position.

(9) a. We don't have a president, \#\#so I am certain the president is not John.

b. We definitely have a president; I don't know if our president is Bill or someone else, but I am certain the president is not John.

While (9b) implies what (8b) implies, (9a) doesn't imply what (8a) implies - in fact, it is quite odd - because the president cannot be used as a predicate in (9a): it presupposes - at least in the speaker's mind - existence of a president, but we are told that there is no president. To the extent that ... so I am certain the president is not John is acceptable, negation is understood meta-linguistically. 
To account for these contrasts, we assume that predicational be (be $e_{\mathrm{PRED}}$ ) and specificational be (be $e_{\mathrm{SPEC}}$ ) have the lexical entries in (10) (these entries will be revised in Section 4, when we deal with expressions of higher types).
a. $\left[\left[b e_{\mathrm{SPEC}}\right]\right]:=\left[\lambda \mathrm{y} \in \mathrm{D}_{\mathrm{e}} \cdot \lambda \mathrm{x} \in \mathrm{D}_{\mathrm{e}} \cdot \mathrm{x}=\mathrm{y}\right]$
b. $\left[\left[b e_{\mathrm{PRED}}\right]\right]:=\left[\lambda \mathrm{Y} \in \mathrm{D}_{<\mathrm{e}, \mathrm{t}>} . \lambda \mathrm{x} \in \mathrm{D}_{\mathrm{e}}: \mathrm{x} \in \operatorname{Dom}(\mathrm{Y}) . \mathrm{Y}(\mathrm{x})=\right.$ True $]$

In addition, we assume the standard $\mathrm{F}$ (unctional) $\mathrm{A}$ (pplication) rule, a fairly standard presuppositional meaning for the, and a fairly standard meaning for president (which, unlike be, takes a pronominal world-denoting argument).

(11) FA. For any variable assignment $\mathrm{g}$, if $\alpha$ is a branching node dominating only $\beta$ and $\gamma, \beta$ and $\gamma$ are both in the domain of $[[]]^{g}$, and $[[\beta]]^{\mathrm{g}}$ is a function whose domain contains $[[\gamma]]^{\mathrm{g}}$, then $[[\alpha]]^{\mathrm{g}}=[[\beta]]^{\mathrm{g}}\left([[\gamma]]^{\mathrm{g}}\right)$.

(12) $[[$ the $]]:=\left[\lambda Y \in \mathrm{D}_{<\mathrm{e}, \mathrm{t}>}\right.$ : there is exactly one (contextually relevant) $\mathrm{y} \in \mathrm{D}_{\mathrm{e}}$ such that $\mathrm{Y}(\mathrm{y})=$ True. the unique $\mathrm{x} \in \mathrm{D}_{\mathrm{e}}$ such that $\mathrm{Y}(\mathrm{x})=$ True]

$[[$ president $]]:=\left[\lambda \mathrm{w} \in \mathrm{D}_{\mathrm{s}} . \lambda \mathrm{c} \in \mathrm{D}_{\mathrm{e}} \cdot \lambda \mathrm{x} \in \mathrm{D}_{\mathrm{e}} . \mathrm{x}\right.$ is a president of $\mathrm{c}$ in $\left.\mathrm{w}\right]$

Thus, the meaning obtained for (8b), on its specificational reading, is (14).

$\left[\lambda \mathrm{w} \in \mathrm{D}_{\mathrm{s}} .\left[\left[\text { not }\left[\text { John be } e_{\mathrm{SPEC}} \text { the president }-w_{0}-c_{1}\right]\right]\right]^{[0 \rightarrow \mathrm{w}, 1 \rightarrow \mathrm{c}]}\right]=$

$\left[\lambda w \in D_{s}\right.$ : there is exactly one $x \in D_{e}$ such that $x$ is president of $\mathrm{c}$ in $\mathrm{w}$. John is not the unique $\mathrm{y} \in \mathrm{D}_{\mathrm{e}}$ such that $\mathrm{y}$ is president of $\mathrm{c}$ in $\left.\mathrm{w}\right]$

Presupposition (existence+uniqueness): There is a unique president. Assertion: John and the unique president are distinct.

The presupposition is contributed by the. Since we treat presuppositions as definedness conditions, they are predicted to be immune to negation.

To obtain the meaning of the predicational sentence in (8a) (and the predicational reading of $(8 \mathrm{~b})$ ), let us also assume the following: as long as no other constraints prevent it, the definite determiner in post-copular position may optionally be invisible to the semantics. ${ }^{3}$ This assumption is supported by the well-formedness of John is president which seems to have a meaning very close to one of the meanings of John is the president. Thus, we derive (15) for (8a): since the is not interpreted, there is no existence presupposition. ${ }^{4}$

$$
\left[\lambda \mathrm{w} \in \mathrm{D}_{\mathrm{s}} .\left[\left[\text { not }\left[\text { John be } e_{\mathrm{PRED}} \text { president }-\mathrm{w}_{0}-c_{1}\right]\right]\right]^{[0 \rightarrow \mathrm{w}, 1 \rightarrow \mathrm{c}]}\right]=
$$

\footnotetext{
${ }^{3}$ The assumption that the is sometimes invisible to semantics is often adopted in order to account for the absolute/comparative ambiguity of superlatives as in John climbed the highest mountain. In the comparative reading (which implies that John is the best mountain-climber), the seems to make no contribution to the meaning (Szabolsci 1986, Heim 1999).

4 'Role'-predicates (king, committee-chair, president etc.) usually come with an 'at-most-one' presupposition which is sometimes suspended and which causes John is not the president to imply that either someone else is the president or that there is no president. This presupposition is not reflected in either (13) or (15). When it is suspended, the cannot be invisible to semantic interpretation (hence the oddity of We have two kings, but John is not the king).
} 
$\left[\lambda w \in D_{s} . J o h n\right.$ is not a president of $\mathrm{c}$ in $\left.w\right]$

Presupposition: --

Assertion: John is not a president.

To sum up so far: (i) because our theory allows the to be invisible to semantic interpretation, we predict that a predicational reading is, in principle, possible when the post-copular phrase is a definite description (e.g., (8a)); and (ii) because predicational be is asymmetrical (see (10)) - only its first argument (i.e., its syntactic sister) can be a "predicate" - we never obtain a predicational reading in cases where the definite description is sitting in the subject position (e.g., (9a)).

Not all definite descriptions in post-copular position easily lend themselves to this ambiguity. Crucially, the only/P-est/first-NPs pattern with the president in that they easily lend themselves to it. As (16) shows, the only woman contrasts with the woman in that only the former may have a predicational reading: when the context allows it, the may be ignored by the semantics in the only woman-descriptions but not in the woman-descriptions. ${ }^{5}$

a. John went out with only one woman last night. I thought it was Sue, but then I found out that Sue was with Fred last night...

... so it seems that Sue was not the only woman John went out with.

... so it seems that Sue was not the woman John went out with.

b. John went out with Sue and some other woman last night...

... so it seems that Sue was not the only woman John went out with.

\# ... so it seems that Sue was not the woman John went out with.

c. John didn't go out with anyone last night...

\#\# ... so it seems that Sue was not the only woman John went out with.

\# ... so it seems that Sue was not the woman John went out with.

(16a) sets up a context where John dated exactly one woman; indeed both the only woman John went out with and the woman John went out with may be used non-predicatively. (16b) sets up a context where John dated two women, so a non-predicative use of the (only) woman John went out with is not possible. However, the only woman John went out with may be used predicatively, whereas the woman John went out with may not. (16c) sets up a context where John didn't date anyone. This rules out a non-predicative use of the (only) woman John went out with. A predicative use of the only woman John went out with is also ruled out in this case, presumably because only presupposes existence independently of the.

As (10) leads us to expect, no definite description in subject position can be understood as a predicate: a definite pre-copular phrase is incompatible with a situation where John dates no woman or more than one woman.

(17) a. John went out with only one woman last night. I thought it was Sue, but then I found out that Sue was with Fred last night...

5 Why 'role'-descriptions (such as the president), the only-descriptions and 'relational'-descriptions (such as my brother) allow the-"deletion", while other descriptions (e.g., the woman) do not, is a difficult and interesting question, which we do not attempt to answer here. 
... so it seems that the (only) woman he went out with was not Sue.

b. John went out with two women last night...

\# ... so it seems that the (only) woman he went out with was not Sue.

c. John didn't go out with anyone last night....

\# ... so it seems that the (only) woman he went out with was not Sue.

The difference between president and only/P-est/first-NPs seems to be that only the latter presuppose existence (and indeed, John is not my only lover cannot imply that I don't have any lovers at all, while John is not the president can, as we saw, imply that there is no president at all). We therefore assume the presuppositional meaning for only in (18), and we derive the meanings in (19) and (20) respectively for the specificational and predicational readings of Sally is not the only woman John is dating. As before, the is visible to semantics only in the specificational reading.

(19) $\left[\lambda \mathrm{w} \in \mathrm{D}_{\mathrm{s}}\right.$. $\left.\left[\left[\text { not }\left[\text { Sally be } e_{\mathrm{SPEC}} \text { the only woman-John-is-dating- } w_{0}\right]\right]\right]^{[0 \mathrm{w}]}\right]=$ $\left[\lambda w \in D_{s}\right.$ : there is exactly one $x \in D_{e}$ such that $x$ is a woman in $w$ and John is dating $\mathrm{x}$ in $\mathrm{w}$. Sally is not the unique woman $\mathrm{y} \in \mathrm{D}_{\mathrm{e}}$ such that John is dating $\mathrm{y}$ in $\mathrm{w}]$

Presupposition (existence+uniqueness): John is dating exactly one woman. Assertion: John is not dating Sally.

(20) $\left[\lambda \mathrm{w} \in \mathrm{D}_{\mathrm{s}}\right.$. $\left.\left[\left[\text { not }\left[\text { Sally be } e_{\mathrm{PRED}} \text { only woman-John-is-dating- } \mathrm{w}_{0}\right]\right]\right]^{[0 \rightarrow \mathrm{w}]}\right]=$ $\left[\lambda \mathrm{w}_{\mathrm{w}} \mathrm{D}_{\mathrm{s}} . \neg\left(\left[\left[\text { only woman-John-is-dating- } w_{0}\right]\right]^{[0 \rightarrow \mathrm{w}]}(\right.\right.$ Sally $\left.\left.)\right)\right]=$ $\left[\lambda \mathrm{w} \in \mathrm{D}_{\mathrm{s}}\right.$ : Sally $\in\left\{\mathrm{y} \in \mathrm{D}_{\mathrm{e}} \mid \mathrm{y}\right.$ is a woman in $\mathrm{w}$ and John is dating $\mathrm{y}$ in $\left.\mathrm{w}\right\}$. $\{$ Sally $\} \neq\left\{\mathrm{y} \in \mathrm{D}_{\mathrm{e}} \mid \mathrm{y}\right.$ is a woman in $\mathrm{w}$ and John is dating $\mathrm{y}$ in $\left.\left.\mathrm{w}\right\}\right]$

Presupposition (existence; no uniqueness): There is a woman $\mathrm{x}$ such that John is dating $\mathrm{x}$ and $\mathrm{x}$ is Sally.

Assertion: John is dating some woman who isn't Sally.

Thus, the existence presupposition of only and the uniqueness presupposition of the both persist under negation in the specificational reading. Likewise, the existence presupposition of only persists under negation in the predicational reading. However, the predicational reading doesn't imply uniqueness because the makes no semantic contribution, and only doesn't presuppose uniqueness (it asserts it). The uniqueness assertion contributed by only disappears under negation, implying that John is dating more than one woman. But this, of course, is possible only when the only NP appears in post-copular position (see (17)).

Notice that the surface position of negation in (8), (9), (16) and (17) suggests that negation may be non-sentential in these cases, so one could argue that we shouldn't expect it to scope above the subject anyway (regardless of what (10) leads us to expect). It is therefore important that we use other tests to show that there is an asymmetry between definite DPs in pre- and post-copular 
positions. Let us, then, apply the Wait-a-Minute test (von Fintel 2004) and the should-test, which involve "semantic" sentential negation. The Wait-a-Minute test is applied in (21) to a Yes/No interrogative (whether- $p$ denotes a subset of $\left\{\left[\lambda \mathrm{w} \in \mathrm{D}_{\mathrm{s} .}[[p]](\mathrm{w})=\right.\right.$ True $],\left[\lambda \mathrm{w} \in \mathrm{D}_{\mathrm{s}} .[[p]](\mathrm{w})=\right.$ False $\left.]\right\}$; see Karttunen 1977 among others). (21) shows that a Wait a minute! response to a Yes/No interrogative is appropriate when Wait a minute! questions what the interrogative presupposes; that is, it questions an assumption shared by both "positive" and "negative" alternatives (in this case, that France has a king). It is inappropriate when Wait a minute! questions an assumption not shared by both alternatives. ${ }^{6}$

A: Is the King of France bald?

( $\{$ France has a bald king, France has a king but he is not bald $\}$ )

B: Wait a minute! You are assuming something I'm not: that France has a king!

B': \#Wait a minute! You are assuming something I'm not: that the King of France is bald/not bald!

The application of this test in (22)-(24) shows the following. Is Sally the only woman John is dating? is ambiguous. On its specificational reading, the assumption shared by both alternatives is that John is dating exactly one woman. On its predicational reading, the assumption shared by both alternatives is that John is dating Sally. These assumptions cannot co-exist in one single reading, because the specificational reading "seeks" the identity of the single woman John is dating, and the predicational reading "seeks" to settle the issue of whether John is dating other women besides Sally. Is Sally the woman John is dating? is unambiguously specificational (doesn't presuppose that John is dating Sally). Likewise, Is the (only) woman John is dating Sally? is unambiguously specificational (doesn't presuppose that John is dating Sally). Thus, only the only-inverse Yes/No interrogative has a predicational reading.

A: Is Sally (really) the only woman John is dating?

B: Wait a minute! You are assuming something I'm not: that John is dating Sally! (Predicational)

B': Wait a minute! you are assuming something I'm not: that John is dating one woman only! (Specificational)

A: Is Sally (really) the woman John is dating?

B: \#\#Wait a minute! You are assuming something I'm not: that John is dating Sally!

B': Wait a minute! You are assuming something I'm not: that John is dating one woman only!

A: Is the (only) woman John is dating (really) Sally?

B: \#\#Wait a minute! You are assuming something I'm not: that John is dating Sally!

\footnotetext{
6In Potts (2008) some doubts are expressed regarding the validity of the Wait-a-Minute test. It is argued that a Wait a minute! response is sometimes appropriate when used to question the validity of assertions. For reasons of space we cannot address these concerns in detail, but many of them are avoided anyway by applying the test to interrogative sentences (which have presuppositions but do not assert) rather than declaratives (which obviously assert).
} 
B': Wait a minute! You are assuming something I'm not: that John is dating one woman only!

The should-test relies on the fact that in a negated should-statement, negation is interpreted below should - which is a Neg-raising verb - but above the embedded subject. Thus, the "negative" alternative in (25b) reflects the fact that semantically, negation is located between should and anyone. ${ }^{7}$

a. Should anyone ever visit France?

b. Alternatives:

\{'the desired/required state of affairs is such that someone visits France at some point', 'the desired/required state of affairs is such that no one ever visits France'\}

Our expectation is, then, that in the context set up in (26), only definite descriptions that may lose their existence presuppositions be able to support a reading the questions the justification of the law (i.e., what is required), giving rise to a predicational reading of Should Linguistics be my only major?, in additional to a specificational one. Indeed, definite only-less descriptions in post-copular position and both kinds of descriptions in subject position cannot be used in this way: both give rise only to a specificational reading. ${ }^{8}$

(26) I am majoring in Linguistics, and I am required to have exactly one major.

a. Should Linguistics really be my only major?

No way! It's not good to have just one major.

No way! Math should be your only major.

b. Should Linguistics really be my major?

(Predicational)

(Specificational)

No way! \#It's not good to have just one major.

No way! Math should be your major.

c. Should my (only) major really be Linguistics?

No way! \#It's not good to have just one major.

No way! Your (only) major should be Math.

To sum up so far, when a definite noun phrase belongs to the class of definites that can function as predicates, the definite determiner may be invisible to semantic interpretation. This cannot happen when the same definite is in pre-copular position, because there is no version of be that "predicates" a pre-copular phrase of a post-copular phrase. Therefore, only-standards cannot have a predicational reading, but only-inverses can.

${ }^{7}$ The alternatives in (25b) rely on a semantic theory of Neg-raising (e.g., Bartsch 1973). Accordingly, $[$ should $]:=\left[\lambda \mathrm{p} \in \mathrm{D}_{<\mathrm{s}, \triangleright} . \lambda \mathrm{w} \in \mathrm{D}_{\mathrm{s}}: \mathrm{ACC}_{\mathrm{w}} \subseteq\left\{\mathrm{w}^{\prime} \in \mathrm{D}_{\mathrm{s}} \mid \mathrm{p}\left(\mathrm{w}^{\prime}\right)=\right.\right.$ True $\}$ or $\mathrm{ACC}_{\mathrm{w}} \subseteq$ $\left\{\mathrm{w}^{\prime} \in \mathrm{D}_{\mathrm{s}} \mid \mathrm{p}\left(\mathrm{w}^{\prime}\right)=\right.$ False $\} . \mathrm{ACC}_{\mathrm{w}} \subseteq\left\{\mathrm{w}^{\prime} \in \mathrm{D}_{\mathrm{s}} \mid \mathrm{p}\left(\mathrm{w}^{\prime}\right)=\right.$ True $\left.\}\right]$.

${ }^{8} \mathrm{We}$ have to watch out for the possibility that the existence/uniqueness presupposition of the may be suspended, even in pre-copular position, causing the uniqueness implication of only to disappear, as in It isn't true that my only option is quitting; I have many more options. The possibility to indirectly suspend uniqueness in this way is neutralized by the context set up in (26), but importantly, there is still an asymmetry between pre- and post-copular definite only-descriptions. 
The next section discusses the fact that when only-inverses show Connectivity, they do so on both their specificational and predicational readings.

\section{A Semantic Theory of Connectivity}

\subsection{Predictions and Expectations}

Recall from Section 2 that the type of DP1 in only-standards and only-inverses is not required to be 'e'. Following Partee $(1986,2000)$ and Jacobson (1994), we assume that be is cross-categorial. More concretely, we assume the lexical entries for be in (27), and adjust the meanings of the and only accordingly.

$$
\begin{aligned}
& {\left[\left[b e_{\mathrm{SPEC}}\right]\right]:=\left[\lambda \mathrm{Y} \in \mathrm{D}_{\sigma} \cdot \lambda \mathrm{X} \in \mathrm{D}_{\sigma} \cdot \mathrm{X}=\mathrm{Y}\right] \quad(' \sigma \text { ' stands for any type) }} \\
& {\left[\left[b e_{\mathrm{PRED}}\right]\right]:=\left[\lambda \mathrm{Y} \in \mathrm{D}_{<\sigma, \triangleright} \cdot \lambda \mathrm{x} \in \mathrm{D}_{\sigma}: \mathrm{x} \in \mathrm{Dom}(\mathrm{Y}) . \mathrm{Y}(\mathrm{x})=\text { True }\right]} \\
& {[[\text { the }]](\mathrm{P})(=\mathrm{THE}(\mathrm{P})) \text { is the unique contextually relevant } \mathrm{x} \text { (if there is one) }} \\
& \text { such that } \mathrm{P}(\mathrm{x})=\text { True }\left(\text { where } \mathrm{x} \in \mathrm{D}_{\sigma} \text { and } \mathrm{P} \in \mathrm{D}_{<\sigma, \downarrow}\right) \\
& {[[\text { only }]]:=\left[\lambda \mathrm{P} \in \mathrm{D}_{<\sigma, \triangleright} \cdot \lambda \mathrm{x} \in \mathrm{D}_{\sigma}: \mathrm{x} \in\left\{\mathrm{y} \in \mathrm{D}_{\sigma} \mid \mathrm{P}(\mathrm{y})=\text { True }\right\} .\{\mathrm{x}\}=\left\{\mathrm{y} \in \mathrm{D}_{\sigma} \mid\right.\right.} \\
& \mathrm{P}(\mathrm{y})=\text { True }\}]
\end{aligned}
$$

These assumptions lead to several predictions, some well-known and some new. A well-known prediction, due to Jacobson (1994) (which is indeed borne out), is that in a specificational sentence, a pronoun may be a bound variable without

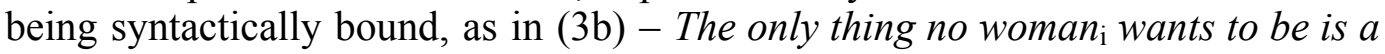
parody of her mother. Jacobson assumes that DP1 (the only thing no woman wants to be, of type $<\mathrm{e},<\mathrm{s},<\mathrm{e}, \mathrm{t}>>>$ ) denotes the one and only function that maps every woman to the single property she doesn't want to have; and DP2 (a parody of her mother, of the same type) denotes the function that maps every woman $\mathrm{x}$ to the property of being a parody of x's mother. Thus, the Connectivity effect exhibited by the specificational reading of the only-standard (3b) is a by-product of interpreting DP1 and DP2 as functions of the same type. Thanks to the assumption that specificational be is symmetrical, Jacobson also predicts that specificational only-inverses (e.g., (1), A parody of her $\mathrm{r}_{\mathrm{i}}$ mother is the only thing no woman $_{\mathrm{i}}$ wants to be) exhibit the same kind of Connectivity effects.

But notice that if Jacobson is right, we are now making a new prediction. The assumption that the in an only-inverse may be invisible to semantic interpretation predicts that NP1 (only thing no woman wants to be, of type $<<\mathrm{e},<\mathrm{s},<\mathrm{e}, \mathrm{t}>>>, \mathrm{t}>$ ) can serve as a predicate that applies to DP2 (a parody of her mother, of type $<\mathrm{e},<\mathrm{s},<\mathrm{e}, \mathrm{t}>>>)$ ). This, in turn, means that $A$ parody of her $\mathrm{i}_{\mathrm{i}}$ mother

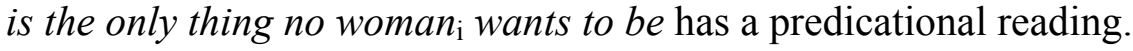

Section 4.2 spells out the theory of Connectivity that derives Jacobson's facts, and our (newly predicted) fact. In 4.3 we apply the Wait-a-Minute test and the should-test to those only-inverses that exhibit Connectivity, to support the claim that they indeed have a predicational reading. Sections 4.4 and 4.5 address two of the potential theoretical problems that arise within this framework.

\subsection{A Functional Theory of Connectivity}


Let us assume that traces can be "functional" and take (silent) pronominal arguments (we follow the analysis in Chierchia 1993, but the assumption that WH-gaps can be "functional" has its roots in Engdahl 1986 and Groenendijk \& Stokhof 1984). Let us also assume, in the spirit of Jacobson (1994), that pronouns need not be c-commanded by a quantified expression in order to be bound by an abstraction-index (this is only assumed "in the spirit" of Jacobson, because, strictly speaking, there are no "variables" in the object language, in her system). This means that the NP only (thing) no woman wants to be can have the LF and interpretation in (30a) (where $t_{2}$ is of type $<\mathrm{e},<\mathrm{s},<\mathrm{e}, \mathrm{t}>>>>$ and $\mathrm{pro}_{3}$ of type e), and a parody of her mother can have the LF (where her is bound by an abstraction-index) and interpretation in (30b). Notice that want is Neg-raising, but for simplicity its special presuppositions (see Footnote 7) are ignored in (30a).

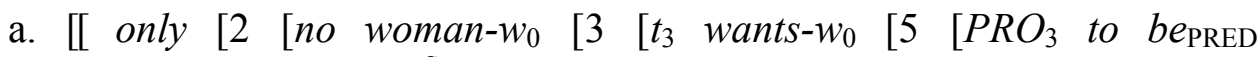
$\left[\left[t_{2}\right]-\right.$ pro $\left.\left.\left.\left.\left.\left.\left.\left.\left._{3}\right]-w_{5}\right]\right]\right]\right]\right]\right]\right]\right]^{\mathrm{g}}=\left[\lambda \mathrm{f} \in \mathrm{D}_{<\mathrm{e},<\mathrm{s},<\mathrm{e}, \mathrm{t}>>>}: \mathrm{f} \in\left\{\mathrm{h} \in \mathrm{D}_{<\mathrm{e},<\mathrm{s},<\mathrm{e}, \mathrm{t}>>>} \mid\right.\right.$ no woman $\mathrm{x}$ in $\mathrm{g}(0)$ is such that for all worlds w' compatible with what $\mathrm{x}$ wants in $\mathrm{g}(0), \mathrm{h}(\mathrm{x})\left(\mathrm{w}^{\prime}\right)(\mathrm{x})=$ True $\} .\{\mathrm{f}\}=\left\{\mathrm{h} \in \mathrm{D}_{<\mathrm{e},<\mathrm{s},<\mathrm{e}, \mathrm{t}>>>} \mid\right.$ no woman $\mathrm{x}$ in $g(0)$ is such that for all worlds $w$ ' compatible with what $x$ wants in $\mathrm{g}(0), \mathrm{h}(\mathrm{x})\left(\mathrm{w}^{\prime}\right)(\mathrm{x})=$ True $\left.\}\right]$

b. [[ $14\left[\right.$ a parody-w $w_{4}$ of her 1 mother $\left.\left.\left.-w_{4}\right]\right]\right]=\left[\lambda \mathrm{x} \in \mathrm{D}_{\mathrm{e}} . \lambda \mathrm{v} \in \mathrm{D}_{\mathrm{s}} \cdot \lambda \mathrm{y} \in \mathrm{D} \cdot \mathrm{y}\right.$ is a parody in $\mathrm{v}$ of $\mathrm{x}$ 's mother in $\mathrm{v}]$

Thus, the specificational reading of the only-standard in (3b) - The only thing no woman wants to be is a parody of her mother (which is also the specificational reading of the only-inverse in (1) - A parody of her mother is the only thing no woman wants to be) - is obtained as in (31).

$\left[\lambda w \in \mathrm{D}_{\mathrm{s}} .\left[\left[\left[\left[\right.\right.\right.\right.\right.$ the only $\left[2\left[\right.\right.$ no woman $-w_{0}\left[3\left[t_{3}\right.\right.$ wants $-w_{0}\left[5\left[P R O_{3}\right.\right.$ to be $e_{\mathrm{PRED}}$ $\left[\left[t_{2}\right]-\right.$ pro $\left.\left.\left.\left.\left.\left.\left.\left._{3}\right]-w_{5}\right]\right]\right]\right]\right]\right]\right]$ be $\mathrm{SPEC}\left[14\left[\right.\right.$ a parody- $w_{4}$ of her ${ }_{1}$ mother $\left.\left.\left.\left.\left.\left.-w_{4}\right]\right]\right]\right]\right]^{[0 \rightarrow \mathrm{w}]}\right]=$ $\left[\lambda \mathrm{w} \in \mathrm{D}_{\mathrm{s}}\right.$. THE([[only $\left[2\right.$ [no woman-w $w_{0}\left[3\left[t_{3}\right.\right.$ wants- $w_{0}\left[5\left[\mathrm{PRO}_{3}\right.\right.$ to be $e_{\mathrm{PRED}}$

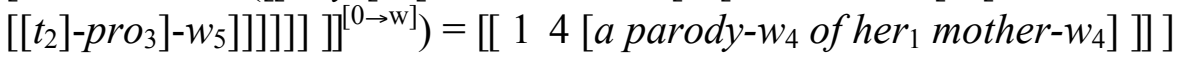

Since we assume that predicational only-inverses have an LF of the form [[DP2 ... be $e_{\text {PRED }}[\mathrm{DP} 1$ [NP1 ...]]], it follows that if DP2 contains an "abstracted-over" pronoun (e.g., (30b)) and NP1 denotes a property of functions of the right type (e.g., (30a)), Connectivity arises. Indeed (1), A parody of her mother is the only thing no woman wants to be, exhibits Connectivity on both its readings.

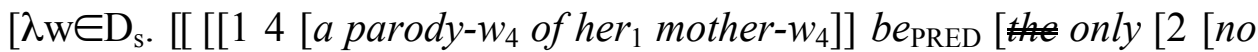
woman- $w_{0}\left[3\left[t_{3}\right.\right.$ wants $-w_{0}\left[5\left[\mathrm{PRO}_{3}\right.\right.$ to be $e_{\mathrm{PRED}}\left[\left[t_{2}\right]-\right.$ pro $\left.\left.\left.\left.\left.\left.\left.\left.\left.\left._{3}\right]-w_{5}\right]\right]\right]\right]\right]\right]\right]\right]^{[0 \rightarrow \mathrm{w}]}\right]$ $=\left[\lambda \mathrm{w} \in \mathrm{D}_{\mathrm{s}}\right.$. [[only $\left[2\left[\right.\right.$ no woman-w $w_{0}\left[3\left[t_{3}\right.\right.$ wants $-w_{0}\left[5\left[\mathrm{PRO}_{3}\right.\right.$ to be $e_{\mathrm{PRED}}$ $\left[\left[t_{2}\right]-\right.$ pro $\left.\left.\left.\left.\left.\left.\left.\left.\left.\left._{3}\right]-w_{5}\right]\right]\right]\right]\right]\right]\right]\right]\right]^{[0 \rightarrow \mathrm{w}]}\left(\left[\left[14\left[\right.\right.\right.\right.$ a parody $-w_{4}$ of her 1 mother $\left.\left.\left.\left.\left.-w_{4}\right]\right]\right]\right)\right]$

Our theory, then, predicts predicational readings of only-inverses to show Connectivity effects, because of the crucial assumption that in those cases, the is invisible to semantic interpretation, making it possible for NP1 to be predicated of DP2. In only-standards (such as The only thing no woman wants to be is a parody 
of her mother) DP2 may also function as a predicate, but only if it doesn't contain a pronoun "bound" by a quantifier in DP1 (recall the contrast between (3b) and $(3 \mathrm{c}))$.

\subsection{Applying "Predicatehood" Tests to Only-inverses with bound pronouns}

As expected, those only-inverses that exhibit variable-binding Connectivity pass the "predicatehood" tests; only-standards do not. As (33) shows, when the only thing no woman wants to be is in post-copular position, a Wait a Minute! response which questions the presupposition that no woman wants to be a parody of her mother is appropriate. Such a response is inappropriate when DP1 is the thing no woman wants to be, or when DP1 is in an only-standard (i.e., in subject position).

a. A: Is a parody of her mother (really) the only thing no woman wants to be?

B: Wait a minute! You are assuming something I'm not: that no woman wants to be a parody of her mother.

b. A: Is a parody of her mother (really) the thing/what no woman wants to be?

B: \#\#Wait a minute! You are assuming something I'm not: that no woman wants to be a parody of her mother.

c. A: Is the (only) thing no woman wants to be (really) a parody of her mother?

B: \#\#Wait a minute! You are assuming something I'm not: that no woman wants to be a parody of her mother.

Likewise, as expected, only a definite only NP-description in the scope of should, in post-copular position, can be used to question the justification of the law described in the context set up in (34). A definite only-less NP-description cannot; and the same holds of a definite only NP-description sitting in subject position neither of them can get rid of the uniqueness presupposition contributed by the.

(34) Every student meets regularly with his advisor. It is, in fact, required that there be exactly one professor that every student meets regularly.

a. Should his advisor really be the only professor every student meets regularly?

Certainly not! It should be the case that there are at least two professors that every student meets regularly.

b. Should his advisor really be the professor every student meets regularly?

Should the (only) professor every student meets regularly really be his advisor?

Certainly not! \#It should be the case that there are at least two professors that every student meets regularly.

\subsection{Is "Specification" a Special Case of Predication?}

Consider again the semantics of $b e_{\mathrm{SPEC}}$ that we assume, repeated in (35). 


$$
\left[\left[b e_{\mathrm{SPEC}}\right]\right]:=\left[\lambda \mathrm{Y} \in \mathrm{D}_{\sigma} \cdot \lambda \mathrm{X} \in \mathrm{D}_{\sigma} \cdot \mathrm{X}=\mathrm{Y}\right]
$$

This symmetrical semantics relies on the assumption that specification is a special case of predication: after all, if we only had predicational be we could account for specificational sentences by saying that in those cases, the post-copular phrase is a $<\sigma, t>$-function whose characteristic set is a singleton set.

Romero (2005) argues against this view (see also Comorovski 2008): according to her, specificational be has its own, non-derivable, semantics. Romero's motivation comes from the existence of (what she calls) Readings A and B of "specificational subjects" (such as the woman Fred thinks is Mary).

a. The woman Fred thinks is Mary is (in fact) Sally. Reading A

b. The woman Fred thinks is Mary is the woman he used to date.

Reading B

Reading A implies that Fred is wrong; Reading B has no such implication.

According to Romero, in (36a), the subject denotes an element of $\mathrm{D}_{<\mathrm{s}, \mathrm{e}>}-$ the function that maps each world $\mathrm{w}$ to the woman Fred identifies in w as Mary; Sally denotes Sally - an element of $\mathrm{D}_{\mathrm{e}}$ (the woman Fred indeed identifies mistakenly as Mary). In (36b), the subject denotes an element of $\mathrm{D}_{<\mathrm{s},<\mathrm{s}, \mathrm{e}>>}-$ the function that maps each world $\mathrm{w}$ to the $<\mathrm{s}, \mathrm{e}>$-function that Fred identifies in $\mathrm{w}$ as the function whose value is Mary; the woman he used to date denotes an element of $\mathrm{D}_{<\mathrm{s}, \mathrm{e}>}-$ the function that maps each world $\mathrm{w}$ to the woman Fred used to date in w (the function Fred indeed identifies, perhaps correctly, as a function whose value is Mary). An appropriate meaning for specificational be is given in (37).

$$
\left[\left[b e_{\text {SPEC }}^{\mathrm{ROM}}\right]\right]:=\left[\lambda \mathrm{w} \in \mathrm{D}_{\mathrm{s}} \cdot \lambda \mathrm{Y} \in \mathrm{D}_{\sigma} . \lambda \mathrm{X} \in \mathrm{D}_{<\mathrm{s}, \mathrm{O}>} . \mathrm{X}(\mathrm{w})=\mathrm{Y}\right]
$$

Accordingly, 'DP1 is DP2', in the specificational sense, asserts that the denotation of DP2 is the result of applying the denotation of DP1 to the world of evaluation.

But notice that Readings A and B can be generated from the symmetrical semantics in (35), as in (38), thanks to the assumption that traces can be "functional" (and to the assumption that pronouns can be freely abstracted over): in the LF underlying Reading A, DP1 denotes a unique individual (as does DP2, namely, Sally) and $t_{2}$ is of type e; in the LF underlying Reading B, DP1 denotes a unique $<\mathrm{s}, \mathrm{e}>$-function (as does DP2, namely, the woman he used to date, whose world argument is bound by an abstraction-index), and $t_{2}$ is of type $<\mathrm{s}, \mathrm{e}>9$

$\underline{\text { Reading A }}$

$\left[\lambda \mathrm{w} \in \mathrm{D}_{\mathrm{s}} \cdot\left[\left[\left[\mathrm{DP} 1\right.\right.\right.\right.$ the woman-w $w_{0}\left[2\right.$ [Fred thinks-w $w_{0}\left[1\left[t_{2}\right.\right.$ be $e_{\mathrm{SPEC}}$ Mary $\left.\left.\left.]\right]\right]\right]$ be $e_{\mathrm{SPEC}}[\mathrm{DP} 2$ Sally $\left.\left.]\right]^{[0 \rightarrow \mathrm{w}]}\right]=$

$\left[\lambda w \in D_{s}\right.$. $\operatorname{THE}\left(\left[\lambda x \in D_{e} \cdot x\right.\right.$ is a woman in $w$ and there is an acquaintance relation $\mathrm{R} 1$ and an acquaintance relation $\mathrm{R} 2$ such that:

(i) $\mathrm{x}$ is the unique $\mathrm{y} \in \mathrm{D}_{\mathrm{e}}$ such that $\mathrm{R} 1(\mathrm{w})(\mathrm{y})($ Fred $)=$ True;

${ }^{9}$ WOMAN is of type $<\mathrm{s},<<\mathrm{s}, \mathrm{e}>, \mathrm{t}>>-$ a property of individual-concepts, and woman is of type $<\mathrm{s},<\mathrm{e}, \mathrm{t}>>-$ a property of individuals. 
(ii) Mary is the unique $y \in \mathrm{D}_{\mathrm{e}}$ such that $\mathrm{R} 2(\mathrm{w})(\mathrm{y})($ Fred $)=T r u e$; and

(iii)for all worlds w' compatible with what Fred believes in w, the unique $\mathrm{z} \in \mathrm{D}_{\mathrm{e}}$ such that $\mathrm{R} 1\left(\mathrm{w}^{\prime}\right)(\mathrm{z})($ Fred $)=$ True is the unique $\mathrm{z} \in \mathrm{D}_{\mathrm{e}}$ such that Sally]

$$
\left.\left.\mathrm{R} 2\left(\mathrm{w}^{\prime}\right)(\mathrm{z})(\text { Fred })=\text { True }\right]\right)=
$$

\section{$\underline{\text { Reading B }}$}

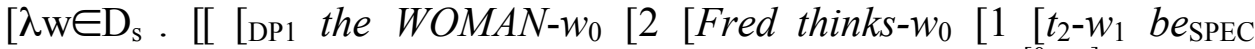
Mary] $]]]$ be $e_{\mathrm{SPEC}}\left[\mathrm{DP} 23\right.$ [the woman- $w_{3}$ he used $-w_{3}$ to date $\left.\left.\left.]\right]\right]^{[0 \rightarrow \mathrm{w}]}\right]=$

$\left[\lambda \mathrm{w} \in \mathrm{D}_{\mathrm{s}} \cdot \operatorname{THE}\left(\left[\lambda \mathrm{f} \in \mathrm{D}_{<\mathrm{s}, \mathrm{e}>} . \mathrm{f}\right.\right.\right.$ is a woman-concept in $\mathrm{w}$ and there is an acquaintance relation $\mathrm{R}$ such that:

(i) Mary is the unique $y \in D_{e}$ such that $\mathrm{R}(\mathrm{w})(\mathrm{y})($ Fred $)=$ True; and

(ii) for all worlds w' compatible with what Fred believes in $w, f(w ')$ is the unique $\mathrm{z} \in \mathrm{D}_{\mathrm{e}}$ such that $\mathrm{R}\left(\mathrm{w}^{\prime}\right)(\mathrm{z})($ Fred $\left.\left.)\right]\right)=$

$\left[\lambda v \in D_{s}\right.$. THE $\left(\left[\lambda x \in D_{e} . x\right.\right.$ is a woman in $v$ and John used to date $x$ in $\left.\left.\left.\left.v\right]\right)\right]\right]$

Furthermore, DP1 in predicational only-inverses may exhibit a Reading A/Reading B ambiguity. Thus, Fred is wrong in (39a), but may be right in (39b).

a. Sally is not the only woman Fred thinks is Mary (he also thinks that Tonya is Mary).

b. The woman he used to date is not the only woman Fred thinks is Mary (he also thinks that the woman he used to work for is Mary).

The ambiguity of DP1 is not a problem for Romero (because, just like us, she could appeal to predicational be to analyze (39)). It only means that even if we followed Romero's suggestion to treat specificational be as asymmetrical, this alone would not suffice to account for every case of A/B-ambiguity.

\subsection{What is "Predicatehood"?}

We have been assuming, crucially, that predicational be is asymmetrical (namely, that a pre-copular phrase can never be "predicated of" a post-copular phrase). This is a non-trivial assumption (and indeed, many researchers believe precisely the opposite; see Footnote 2).

One reason to believe that the subject of a copular sentence cannot be the "predicate" is the fact that only-standards with a post-copular name do not pass the predicatehood tests (see (21)-(26)). More generally, the claim that definite descriptions in subject position are not "predicates" is consistent with Heycock \& Kroch's (1999) observation, illustrated in (40)-(41), that adjectives and indefinite NPs - which are "classical" predicates - do not make good copular subjects (when the post-copular phrase is of a lower type).

(40) a. John is a nuisance.

b. *A nuisance is John.

a. John is Fond of Mary

b. *Fond of Mary is John. 
There are, however, some well-known - real or apparent - counter-examples.

(42) a. Pride and Prejudice is a good book.

b. A good book is Pride and Prejudice.

a. A parody of her mother is something no woman wants to be.

b. Something no woman wants to be is a parody of her mother.

a. The night is tender.

b. (F. Scott Fitzgerald's) Tender is the Night.

Are these merely apparent counter-examples? $(44 a, b)$ probably roughly mean the same "thing", but the latter is poetic and usually not an acceptable way to express what the former means. $(42 \mathrm{a}, \mathrm{b})$ and $(43 \mathrm{a}, \mathrm{b})$, do not mean quite the same "thing": A good book is Pride and Prejudice presupposes that the set of good books is not empty, but Pride and Prejudice is a good book does not (though it is, of course, compatible with such a situation).

It is plausible, then, that $(42 b) /(43 b)$ are specificational sentences, with an analysis along the lines of (45) (for (42b), and a similar analysis for (43b)), where ' $\mathrm{f}^{\text {TYP }}$, stands for a special $<<\mathrm{e}, \mathrm{t}>, \mathrm{e}>$-function, which picks out typical examples (see Comorovski 2008 for a different take on this idea). Support for this view comes from the fact that he in (46a) is interpreted as a bound variable (and given that there is no only in the post-copular phrase, the bound reading should probably be attributed to a specificational reading), and the contrast in grammaticality between (46b) and (46c): the latter has a predicational reading; the former is simply ungrammatical. (46b) cannot have a specificational reading because of a type-mismatch between the pre- and post-copular phrases ( $<\mathrm{e}, \mathrm{t}>\mathrm{vs} .<<\mathrm{e}, \mathrm{t}>, \mathrm{t}>$ ). It cannot have a predicational reading because, presumably, in predicational sentences a quantifier is obligatorily QR'ed leaving behind a trace of type e (a type which is not compatible with $\left.b e_{\mathrm{PRED}}\right)$.

$\mathrm{f}^{\mathrm{TYP}}([[\mathrm{good}$ book $]])=$ 'Pride and Prejudice'

a. A typical book no author likes is the book that he wrote right after his first success.

b. *A nuisance to his friends is every man / no man.

c. Every man / no man is a nuisance to his friends.

Still, other tests are sometimes used to identify predicates in pre-copular position - tests that have been taken to indicate that subjects can be "predicates". Among these tests is the it-anaphora test (Mikkelsen 2005).

The only woman Fred is dating is not Sally; it is Mary / \#she is Mary.

But notice that this example doesn't show that the only woman Fred is dating is a "predicate" (more accurately, it doesn't show that the type of the only woman Fred is dating ends in ' $\mathrm{t}$ '). It merely shows that it can "pick up" as its antecedent the intension of DP1, while she picks up its extension. ${ }^{10}$

\footnotetext{
${ }^{10}$ It is worth noting that there are situations where she is Mary is a felicitous continuation of The only woman Fred is dating is not Sally. For example, when we are at a party and we point at
} 


\section{The Syntactic Account of Connectivity and its Inherent Flaw}

The analysis of Connectivity presented here is part of a more general theory of Connectivity that says that its source is essentially semantic. As is well known, one popular view of Connectivity says that its source is syntactic. The idea within the competing "syntactic" view is that Connectivity arises in specificational sentences because at LF, material from the pre-copular phrase has a copy in the post-copular phrase (so that the "bindable" material in the post-copular phrase is indeed syntactically bound). There are many variants of this approach, but they all share the same basic problem. We therefore present only one of these variants.

Ross (1972) proposes that specificational sentences have a clausal question-answer underlying syntax: the pre-copular phrase is a WH-question, the answer to which is the post-copular phrase. Some portions of the post-copular phrase are elided. Predicational sentences do not have a question-answer syntax.

(48) The only thing no woman wants to be is a parody of her mother.

Specificational underlying structure: her is c-commanded by no woman.

$\left[\left[\mathrm{Q}_{+\mathrm{WH}}\right.\right.$ only thing no woman wants to be $\left.e_{\mathrm{PRED}}\right]\left[\right.$ be $_{\mathrm{SPEC}}[$ homants

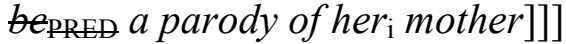

Predicational underlying structure: her is not c-commanded by no woman. *[[the only thing no woman $_{\mathrm{i}}$ wants to be PRED $_{\text {[ }}$ [be $e_{\mathrm{PRED}}$ [a parody of her $\mathrm{i}$ mother]]]

Predicational readings of only-inverses clearly pose a problem for this approach. There is no way to assign A parody of her mother is not the only thing no woman wants to be a predicational structure where her is bound by no woman.

Importantly, the option of abandoning the question-answer idea in favor of long distance QR of no woman is not feasible (see Jacobson 1994 for a similar point). QR'ing no woman long distance leads to counter-intuitive truth conditions for both the predicational ((49a)) and the specificational ((49b)) reading of $A$ parody of her mother is not the only thing no woman wants to be: both come out as implying, incorrectly, that every woman wants to be a parody of her mother.

There is no woman $\mathrm{x}$ such that:

a. $\neg\left(\left[\left[\text { only thing } t_{1} \text { wants to be }\right]\right]^{[1 \rightarrow \mathrm{x}]}\left(\left[\left[\text { a parody of her }{ }_{1} \text { mother }\right]\right]^{[1 \rightarrow \mathrm{x}]}\right)\right)$

b. $\neg\left(\left[\left[\text { a parody of her }{ }_{1} \text { mother }\right]\right]^{[1 \rightarrow \mathrm{x}]}=\left[\left[\text { the only thing } t_{1} \text { wants to be }\right]\right]^{[1 \rightarrow \mathrm{x}]}\right)$

\section{Some Open Questions}

The semantic approach deals well with Bound Pronoun Connectivity. However, there are at least two problems that remain unsolved at this point.

First, Connectivity effects related to Binding Conditions A, B and C are much harder to explain, as illustrated by (50): on its specificational reading, John

someone who (we think) fits the description, but there is a debate among the discourse participants regarding the identity of that person. This fact does not, of course, undermine the claim that it is Mary is often the only felicitous continuation. 
behaves as if it were c-commanded by he, and as if Condition $\mathrm{C}$ prohibited coreference between them.

(50) The only annoying thing he $\mathrm{i}_{\mathrm{i}}$ is is a nuisance to $\mathrm{John}_{\mathrm{i}}$.

$=/=>$ (that property $\mathrm{P}$ such that: $\mathrm{P}(\mathrm{John})$ and annoying $(\mathrm{P}))=($ that property $\mathrm{P}$ such that for all $\mathrm{x}, \mathrm{P}(\mathrm{x})$ iff $\mathrm{x} \in\{\mathrm{y} \mid$ nuisance-to-John(y) $\})$

$==>$ (that property $\mathrm{P}$ such that: $\mathrm{P}(\mathrm{John})$ and annoying $(\mathrm{P})) \in\{\mathrm{y} \mid$ nuisance-to-John $(\mathrm{y})\}$

On the other hand, as Heycock \& Kroch (2002) show, clausal "inverse" specificational sentences escape Condition C violations (see (51)). But Heycock \& Kroch's observation does not generalize to non-clausal "inverse" sentences: both $(52 a)$ and $(52 b)$ are unacceptable.

(51) a. *What he $\mathrm{i}_{\mathrm{i}}$ has always claimed is that $\mathrm{John}_{\mathrm{i}}$ is innocent.

b. That $\mathrm{John}_{\mathrm{i}}$ is innocent is what he $\mathrm{i}_{\mathrm{i}}$ has always claimed.

a. *The only woman she $e_{i}$ likes is (not) Mary .

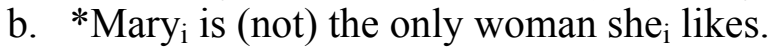

Since (52b) is ill-formed, it seems that Condition $C$ is violated in both its readings. This is not predicted by any existing theory of Connectivity.

The second problem is illustrated by the following contrast.

(53) a. The department was empty. The only student (we ran into) was Mary.

b. The department was empty. \#The student (we ran into) was Mary.

Our proposal does not distinguish between definite subjects with and without only: both are assumed to presuppose existence (which seems fine for (53a), but counter-intuitive for (53b)). Giving up the idea that the only NP presupposes existence would mean giving up the explanation of the contrasts in Section 3.

This problem may perhaps be solved by treating only as more superlative-like than we have so far. The contrast in (54) suggests a solution.

(54) a. We don't have any tall students. The tallest student is Mary.

b. We don't have any tall students. \#The tall student is Mary.

The acceptability of (54a) suggests that tallest student presupposes that there is at least one student who is tall to some degree, which might be very low (see Heim 1999), whereas tall student has no such presupposition (it presupposes, rather, a contextually-determined minimal standard of tallness). Thus, the tallest student requires the hearer to accommodate a reasonable presupposition, namely, that one (short) student is taller than the other (short) students (as opposed to the tall student, which requires an impossible accommodation: the existence of a student who reaches the minimal tallness-standard, in a context where there aren't any such students). If we can claim that only student (as opposed to student) has a similar "degree"-existence presupposition, the contrast in (53) is less surprising.

\section{References}


Bartsch, Renate: 1973. "Negative transportation" gibt es nicht. Linguistische Berichte 27:1-7.

Chierchia, Gennaro: (1993). 'Questions with Quantifiers', Natural Language Semantics 1: 181-234.

Comorovski, Ileana: 2008. 'Constituent questions and the copula of specification', in I. Comorovski and K. von Heusinger (eds.), Existence: Semantics and Syntax, Springer, 49-78.

Engdahl, Elisabet: 1986. Constituent Questions, Kluwer, Dordrecht.

von Fintel, Kai: 2004. 'Would you Believe It? The King of France is Back!' Presuppositions and Truth-value Intuitions. In M. Reimer and A. Bezuidenhout (eds.) Descriptions and Beyond, Oxford University Press.

Fodor, Janet: 1970. The Linguistic Description of Opaque Contexts, Doctoral dissertation, MIT.

Groenendijk, Jeroen and Stokhof, Martin: 1984. Studies in the Semantics of Questions and the Pragmatics of Answers, $\mathrm{PhD}$ dissertation, University of Amsterdam.

Heim, Irene: 1999. 'Notes on Superlatives, ms. MIT.

Heller, Daphna: 2002. On the relation of Connectivity and specificational pseudoclefts. Natural Language Semantics 10: 243-284.

Heycock, Caroline \& Kroch, Anthony: 1999. 'Pseudocleft Connectedness: Implications for the LF Interface Level', Linguistic Inquiry 30:365-397.

Heycock, Caroline \& Kroch, Anthony: 2002. 'Topic, Focus, and syntactic representations', Proceedings of WCCFL 21.

Higgins, Roger: 1973. The Pseudocleft Construction in English, Doctoral Dissertation, MIT.

Jacobson, Pauline. (1994). Binding Connectivity in copular sentences, in M. Harvey and L. Santelmann (eds.), Proceedings of SALT 4, 161-178, Cornell University.

Karttunen, Lauri: 1977. Syntax and Semantics of Questions. Linguistics and Philosophy 1:3-44.

Mikkelsen, Line: 2005. Copular Clauses: specification, predication and equation. Amsterdam: John Benjamins.

Partee, Barbara: 1986. Ambiguous pseudoclefts with unambiguous $\mathrm{BE}$, in $\mathrm{S}$. Berman, J.-W. Choe, and J. McDonough (eds.), Proceedings of NELS 16, pp. 354-366. GLSA, University of Massachusetts Amherst.

Partee, Barbara: 2000. 'Copula Inversion Puzzles in English and Russian', in UMOP 23: Issues in Semantics and its Interface, ed. Kiyomi Kusumoto and Elisabeth Villalta, 198-208. Amherst: GLSA.

Potts, Christopher: (2008). 'Wait a Minute! What Kind of Discourse Strategy is This?', Ms. University of Massachusetts Amherst.

Romero, Maribel. 2005. 'Concealed Questions and Specificational Subjects', Linguistics and Philosophy 28:687-737.

Ross, J.R.: 1972. 'Act', in D. Davidson and G. Harman (eds.) Semantics of Natural Language, Dordrecht: Reidel, 70-126.

Rothstein, Susan: 2004. Predicates and Their Subjects. Kluwer: Dordrecht.

Sharvit, Yael: 1999. 'Connectivity in Specificational Sentences'. Natural Language Semantics 7:299-341. 
Szabolcsi, Anna. 1986. 'Comparative Superlatives', in N. Fukui et al. (eds.), MIT Working Papers in Linguistics, Vol. 8, MIT Press, 245-265. 